\title{
FE-INVESTIGATION OF SEMI CIRCULAR CURVED BEAM SUBJECTED TO OUT-OF-PLANE LOAD
}

\author{
Rakshith $\mathbf{N}^{1}$, Chethan $\mathrm{S}^{2}$, Manjunatha $\mathbf{H S}^{3}$, Suresh Kumar $\mathbf{S}^{\mathbf{4}}$ \\ ${ }^{1}$ Assistant Professor, Department of Mechanical Engg, ATME College of engineering, MYSORE, Karnataka, India. \\ ${ }^{2}$ Assistant Professor, Department of Mechanical Engg, ATME College of engineering, MYSORE, Karnataka, India. \\ ${ }^{3}$ Assistant Professor, Department of Mechanical Engg, ATME College of engineering, MYSORE, Karnataka, India. \\ ${ }^{4}$ Assistant Professor, Department of Mechanical Engg, ATME College of engineering, MYSORE, Karnataka, India.
}

\begin{abstract}
Curved beams are used as machine or structural members in many applications. Based on application of load they can be classified into two categories. Curved beams subjected to In-Plane loads are more familiar and are used for crane hooks, Cclamps etc. The other categories of curved beams are the ones that are subjected to out-of-plane loads. They find applications in automobile universal joints, raider arms and many civil structures etc.The results of this research on semicircular curved beam subjected to out-of-plane loads have revealed some interesting results. For semicircular curved beams subjected to out-of-plane loads, it is shown that every section is subjected to a combination of transverse shear force, bending moment and twisting moment. By using ANSYS tool it is shown that Maximum principal stress occurs at section 120 degrees from the section containing the loading line. Moreover it is observed that fixed end of this curved beam is subjected to a state of pure shear.
\end{abstract}

Key Words: Semi circular curved beam, Stress in curved beam, Out-of-plane load, FE analysis.

\section{INTRODUCTION}

Curved beams are the parts of machine members found in $\mathrm{C}$ clamps, crane hooks, frames of presses, punching machines, planers automobile components etc. In straight beams the neutral axis of the section coincides with its centroidal axis and the stress distribution in the beam is linear. But in the case of curved beams the neutral axis of is shifted towards the centre of curvature of the beam causing a non linear distribution of stress. Rakshith et al.[1]derived an expression for semi circular curved beam subjected to out of plane load. Fonseca et al. [2] studied curved pipes subjected to in-plane loads, Stefano Lenci et al.[3] a 3-d mechanical model of curved beam is analysed by them, Saffari et al.[4] sudies by using circular arc element based on trignometric functions foe in-plane loads, Clive et al.[5] investigated end loaded shallow curved beams of in-plane load type, Öz et al.[6] analysed in plane vibrations of curved beam having open crack, Aimin Yu et al.[7] made a work on naturally twisted curved beams of thin walled sections that of inplane loads.

Stress analysis of curved beams subjected to out-of-plane loads also is important as such beams are used in many machine and structural applications. This paper attempts to analyse the stresses induced in such a curved beam by using analysis tool Ansys.

\subsection{Assumptions}

Some of the assumptions made to derive expression of principle stress for curved beam subjected to Out-Of-Plane load case are as follows,
$>$ The radius of curvature is assumed much larger than the section radius.

$>$ The material is assumed to be linearly elastic.

$>$ The beam is assumed to be geometrically planar, i.e., the un-deformed axis of the beam is assumed to be a circle lying in the plane of the beam.

$>$ The cross section is assumed to be constant and with the same orientation with respect to the plane of the beam, so that there is no initial torsion..

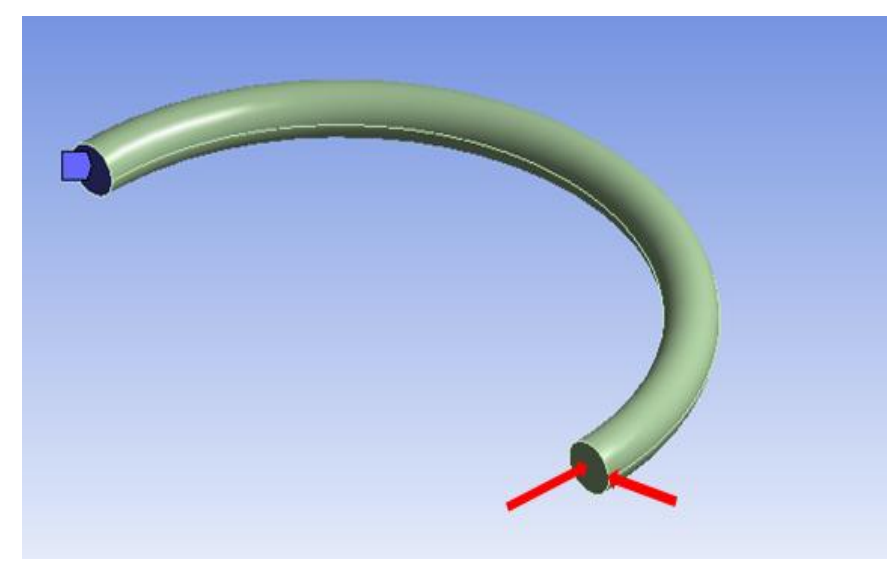

Figure 1: Curved beam with In-Plane load 


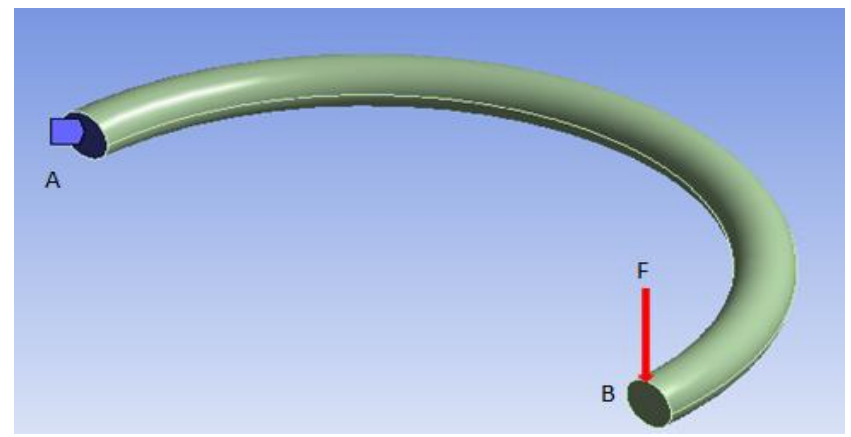

Figure 2: Curved beam with Out-Of-Plane load

\section{EXPRESSION FOR OUT-OF-PLANE}

\section{LOAD CONDITION}

A semi circular curved beam of circular cross section lying in the plane of paper as shown in figure 3(a). The beam is fixed at one end ' $A$ ' and an out-of-plane load ' $F$ ' is applied at the other end ' $\mathrm{B}$ ' [1].

$\mathrm{F}=$ Applied load in $\mathrm{N}$

$\mathrm{R}_{\mathrm{o}}=$ Outer radius of beam in $\mathrm{mm}$.

$\mathrm{R}_{\mathrm{m}}=$ Mean radius of beam in $\mathrm{mm}$

$\mathrm{R}_{\mathrm{i}}=$ Inner radius of beam in $\mathrm{mm}$.

$\alpha=$ angle made by the section X-X w.r.t loading line.

$\mathrm{d}=$ diameter at any section $\mathrm{X}-\mathrm{X}$.

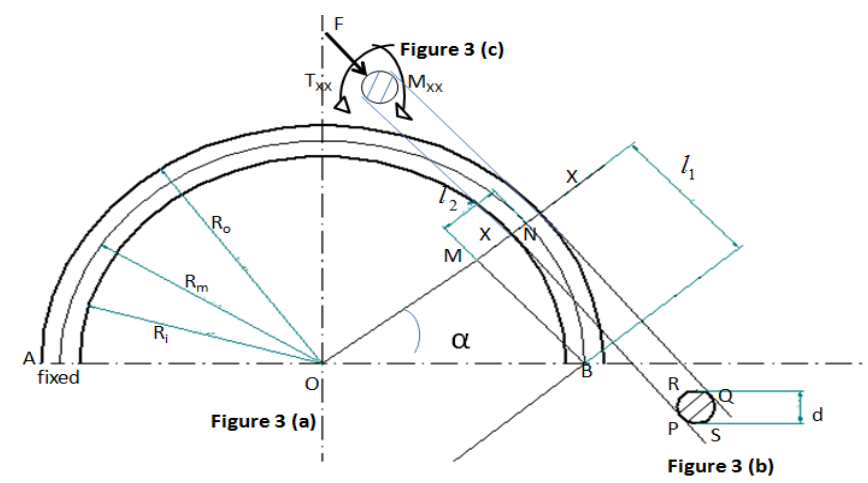

Figure 3(a): Detailed view of semi circular beam.

Figure 3(b): Cross section of beam at X-X with Extreme points indicated.

Figure 3(c): Loads and moments acting on cross section $\mathrm{X}$ $\mathrm{X}$

Let $\mathrm{X}-\mathrm{X}$ be a plane passing through the centre of curvature and perpendicular to cross section of the beam. Let the angle made by this plane $\mathrm{X}-\mathrm{X}$ wit respect to the free end be $\alpha$ as shown in fig 3(b). The effect of Out-Of-Plane load $F$ at the section is to cause $\mathrm{i}$ ). Transverse shear due to direct force $\mathrm{F}$. ii) A bending moment $M_{X X}$ and iii) A twisting moment $T_{X X}$ as shown in fig 3(c). The magnitudes of the stresses due to these loads can be given by,

$$
\sigma_{1,2}=K\left[\sin \alpha \pm 2 \sin \frac{\alpha}{2}\right]
$$

Where, $\quad K=\left[\frac{16 F R_{m}}{\pi d^{3}}\right]$

\section{FE ANALYSIS OF CURVED BEAM SUBJECTED TO OUT-OF-PLANE LOAD}

\section{Modeled Geometry}

The specimen geometry is created using 3-d modeling software PROE-WILDFIRE-5 according to the dimensions specified below,

$>\mathrm{R}_{\mathrm{i}}$-Inner radius of geometry $=115 \mathrm{~mm}$.

$>\mathrm{R}_{\mathrm{o}}$-Outer radius of geometry $=135 \mathrm{~mm}$.

$>\mathrm{R}_{\mathrm{m}}$-mean radius of geometry $=125 \mathrm{~mm}$.

$>$ d- Cross section diameter $=20 \mathrm{~mm}$.

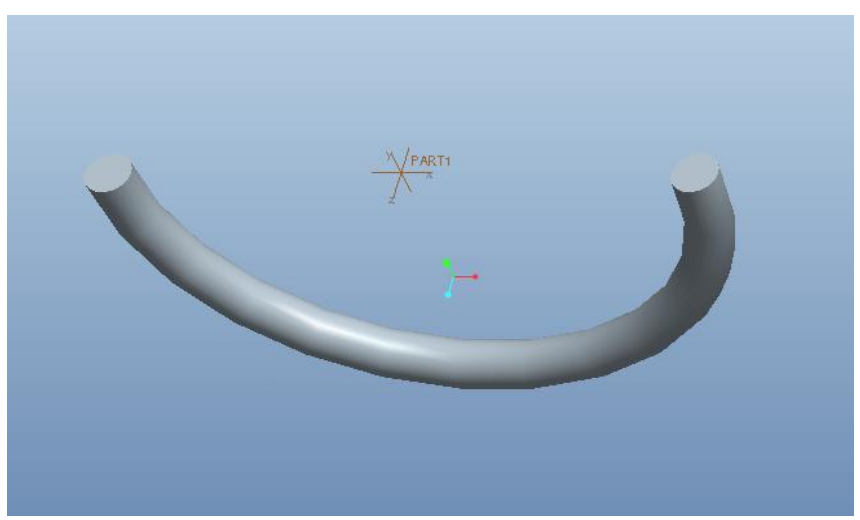

Figure 4.1: 3-D Model Of Specimen Geometry

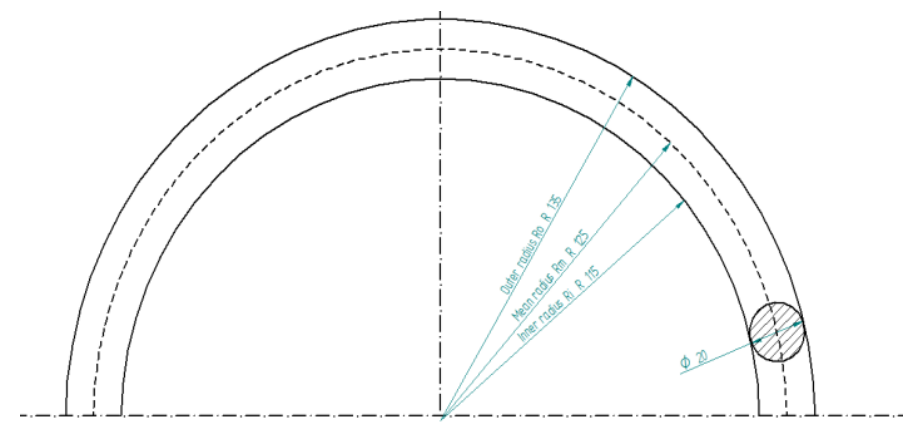

Figure 4.2: 2-D Model Of Specimen Geometry

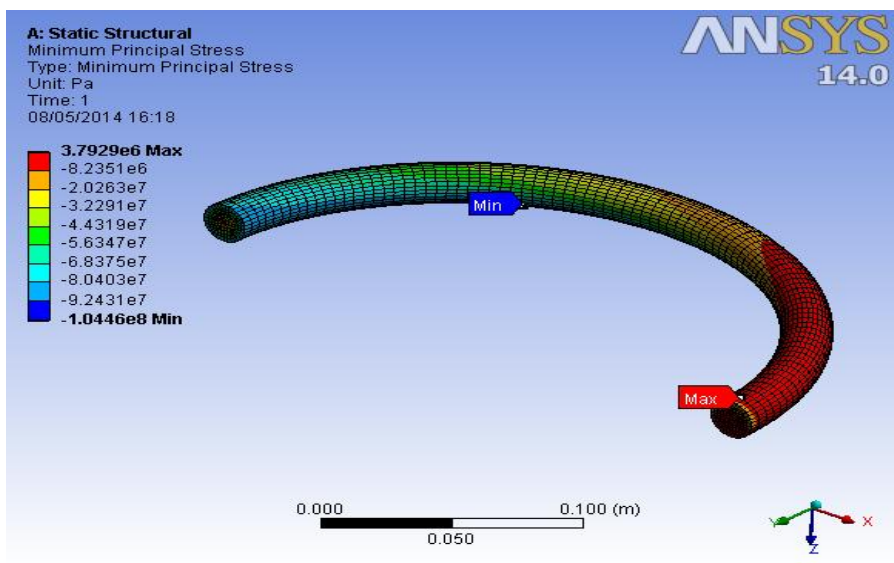

Figure 5: Variation Of Principal Stress In Solved Model Of Curved Beam. 
The following figures 5.1(a) to 5.1(j) shows the maximum Principal stresses and minimum principal stress at different section in accordance with open angle $\alpha$

For $\mathrm{d}=20 \mathrm{~mm} \mathrm{R}_{\mathrm{m}}=125 \mathrm{~mm}, \mathrm{~F}=500 \mathrm{~N}$, and $\alpha=100^{\circ}$
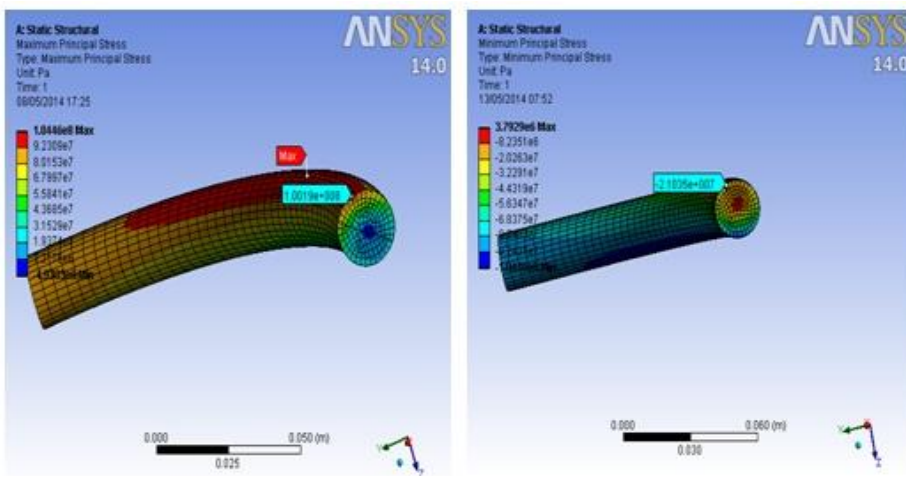

Figure 5.1 (A): Maximum And Minimum Principal Stress For A $-100^{\circ}$ Of Curved Beam.

Maximum principal stress $=100.1 \mathrm{Mpa}$

Minimum principal stress $=-21 \mathrm{Mpa}$

For $\mathrm{d}=20 \mathrm{~mm} \mathrm{R}_{\mathrm{m}}=125 \mathrm{~mm}, \mathrm{~F}=500 \mathrm{~N}$, and $\alpha=110^{\circ}$

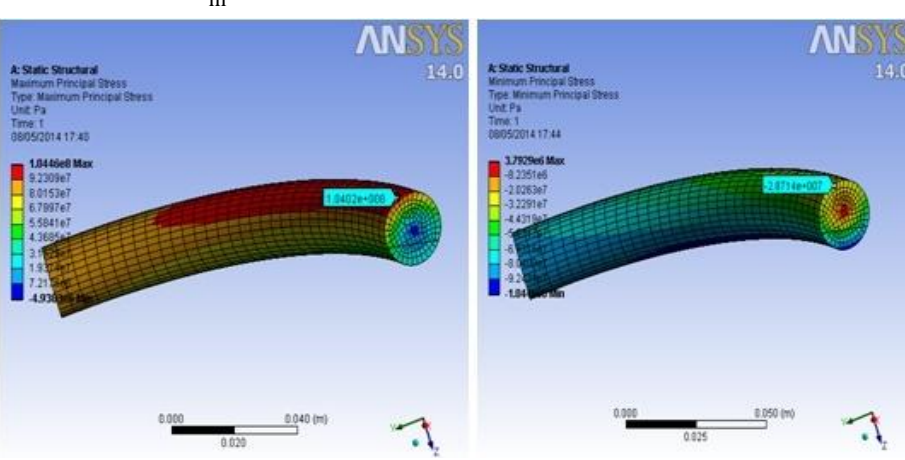

Figure 5.1 (B): Maximum And Minimum Principal Stress For A- $110^{\circ}$ Of Curved Beam.

Maximum principal stress $=104.02 \mathrm{Mpa}$

Minimum principal stress $=-28.71 \mathrm{Mpa}$

For $\mathrm{d}=20 \mathrm{~mm} \mathrm{R}=125 \mathrm{~mm}, \mathrm{~F}=500 \mathrm{~N}$, and $\alpha=120^{\circ}$
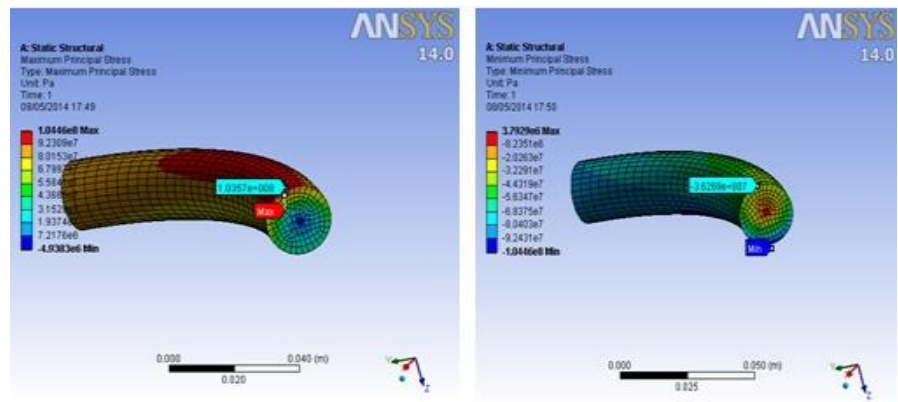

Figure 5.1 (C): Maximum And Minimum Principal Stress For A $-120^{\circ}$ Of Curved Beam.

Maximum principal stress $=103.57 \mathrm{Mpa}$

Minimum principal stress $=-36.26 \mathrm{Mpa}$

For $\mathrm{d}=20 \mathrm{~mm} \mathrm{R}=125 \mathrm{~mm}, \mathrm{~F}=500 \mathrm{~N}$, and $\alpha=130^{\circ}$
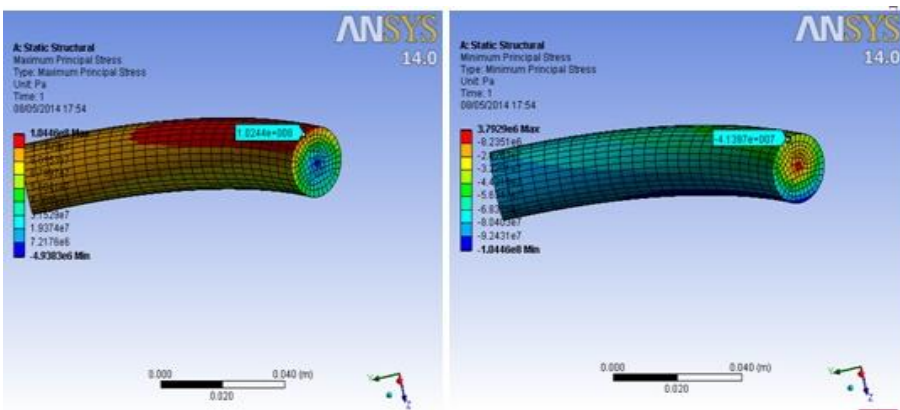

Figure 5.1 (D): Maximum And Minimum Principal Stress For A- $130^{\circ}$ Of Curved Beam.

Maximum principal stress $=102.44 \mathrm{Mpa}$

Minimum principal stress $=-41.39 \mathrm{Mpa}$

For $\mathrm{d}=20 \mathrm{~mm} \mathrm{R}=125 \mathrm{~mm}, \mathrm{~F}=500 \mathrm{~N}$, and $\alpha=140^{\circ}$

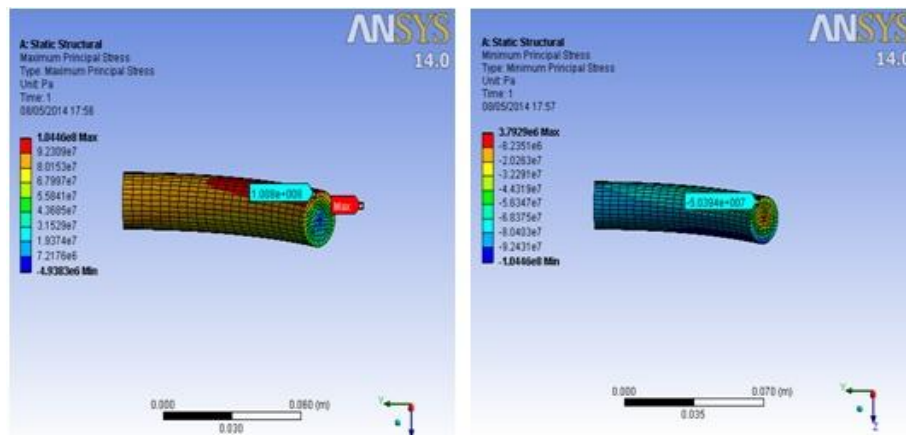

Figure 5.1 (E): Maximum And Minimum Principal Stress For A- $140^{\circ}$ Of Curved Beam.

Maximum principal stress $=100.8 \mathrm{Mpa}$

Minimum principal stress $=-50.39 \mathrm{Mpa}$

For $\mathrm{d}=20 \mathrm{~mm} \mathrm{R}_{\mathrm{m}}=125 \mathrm{~mm}, \mathrm{~F}=500 \mathrm{~N}$, and $\alpha=150^{\circ}$
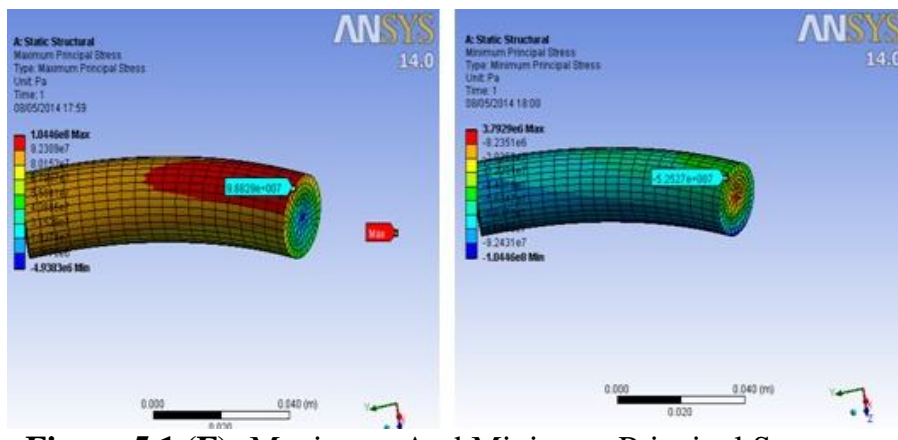

Figure 5.1 (F): Maximum And Minimum Principal Stress For A- $150^{\circ}$ Of Curved Beam.

Maximum principal stress $=96.82 \mathrm{Mpa}$

Minimum principal stress $=-52.3 \mathrm{Mpa}$

For $\mathrm{d}=20 \mathrm{~mm} \mathrm{R}=125 \mathrm{~mm}, \mathrm{~F}=500 \mathrm{~N}$, and $\alpha=160^{\circ}$ 


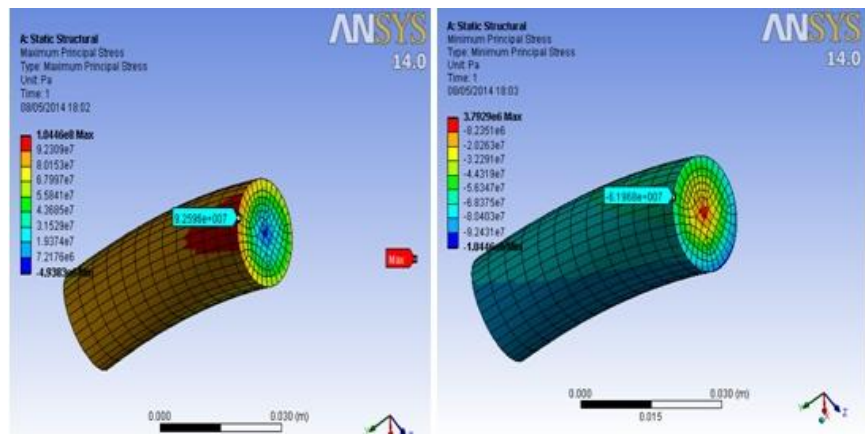

Figure 5.1 (G): Maximum And Minimum Principal Stress For A $-160^{\circ}$ Of Curved Beam.

Maximum principal stress $=92.58 \mathrm{Mpa}$

Minimum principal stress $=-61.98 \mathrm{Mpa}$

For $\mathrm{d}=20 \mathrm{~mm} \mathrm{R}=125 \mathrm{~mm}, \mathrm{~F}=500 \mathrm{~N}$, and $\alpha=170^{\circ}$
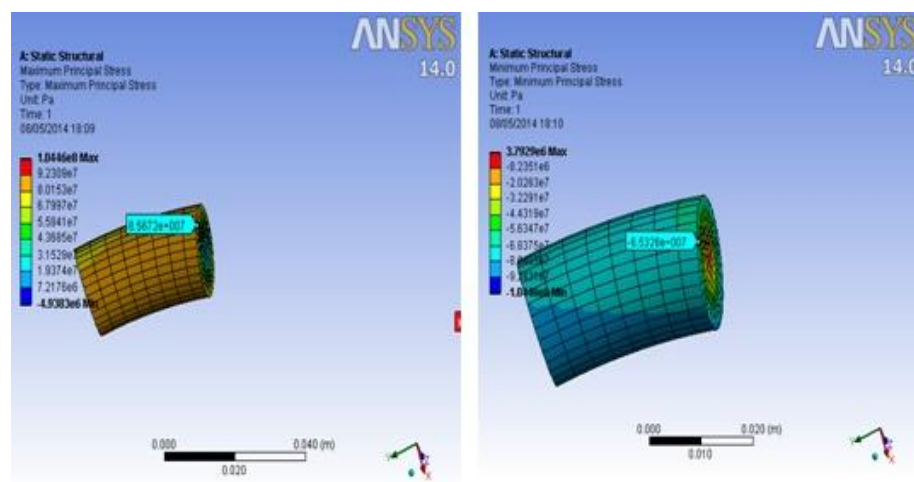

Figure 5.1 (h): Maximum and minimum principal stress for $\alpha-170^{\circ}$ of curved beam.

Maximum principal stress $=85.67 \mathrm{Mpa}$

Minimum principal stress $=-65.32 \mathrm{Mpa}$

For $\mathrm{d}=20 \mathrm{~mm} \mathrm{R}=125 \mathrm{~mm}, \mathrm{~F}=500 \mathrm{~N}$, and $\alpha=180^{\circ}$

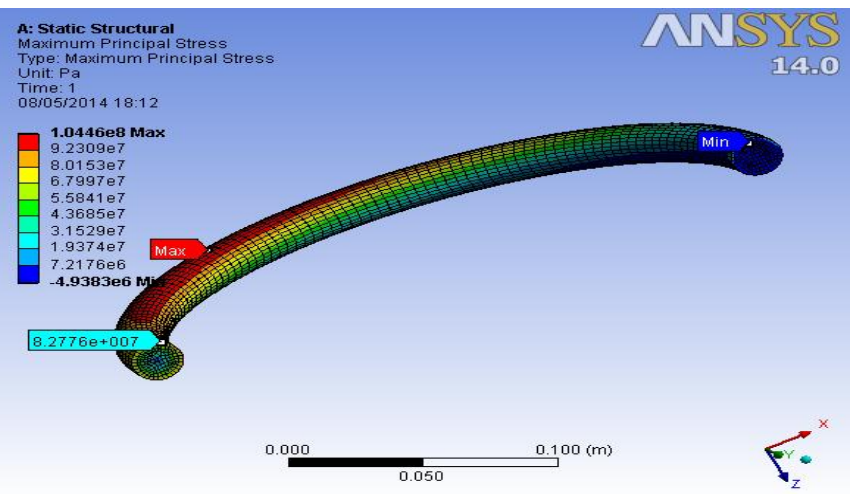

Figure 5.1 (i): Maximum principal stress for $\alpha-180^{\circ}$ of curved beam.

Maximum principal stress $=82.7 \mathrm{Mpa}$

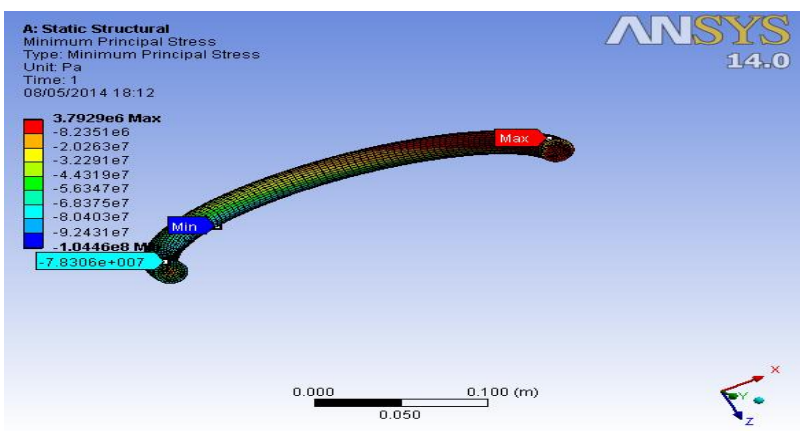

Figure 5.1(J) : Minimum Principal Stress For A- $180^{\circ}$ Of Curved Beam.

Minimum principal stress $=-78.3 \mathrm{MPa}$

\section{Comparisons Of Values Obtained By Theoretical And ANSYS Are Shown In Below Table 1}

Table 1: Comparision Of Numerical Values Of Principal Stresses Obtained By Theoretical And ANSYS Approach.

\begin{tabular}{|c|c|c|c|c|c|c|}
\hline $\begin{array}{l}\alpha(d) \\
\text { eg) }\end{array}$ & $\begin{array}{c}\sigma_{1}(\text { Theore } \\
\text { tical) } \\
\text { Mpa }\end{array}$ & $\begin{array}{c}\sigma_{1}(\text { An } \\
\text { sys }) \\
\text { Mpa }\end{array}$ & $\begin{array}{c}\text { Percen } \\
\text { tage } \\
\text { Error } \\
\%\end{array}$ & $\begin{array}{c}\sigma_{2}(\text { Theore } \\
\text { tical) } \\
\text { Mpa }\end{array}$ & $\begin{array}{c}\sigma_{2}(\text { An } \\
\text { sys }) \\
\text { Mpa }\end{array}$ & $\begin{array}{c}\text { Percen } \\
\text { tage } \\
\text { Error } \\
\%\end{array}$ \\
\hline 10 & 13.84486 & 13.98 & 1.00 & -0.02639 & -0.038 & 3.1 \\
\hline 20 & 27.42701 & 27.54 & 0.43 & -0.20993 & $\begin{array}{c}- \\
0.2185\end{array}$ & 3.9 \\
\hline 30 & 40.4905 & 40.23 & 0.42 & -0.7018 & $\begin{array}{c}- \\
0.7005\end{array}$ & 0.185 \\
\hline 40 & 52.79276 & 53.03 & 0.45 & -1.64139 & $\begin{array}{c}- \\
1.6527\end{array}$ & 0.60 \\
\hline 50 & 64.11077 & 64.2 & 0.14 & -3.15095 & -3.287 & 4.1 \\
\hline 60 & 74.24672 & 74.35 & 0.147 & -5.33068 & -5.457 & 2.2 \\
\hline 70 & 83.03287 & 83.57 & 0.6461 & -8.25457 & -8.983 & 7.3 \\
\hline 80 & 90.33559 & 91.27 & 1.02 & -11.9671 & -12.75 & 6.1 \\
\hline 90 & 96.05842 & 96.125 & 0.07 & -16.481 & $\begin{array}{c}- \\
17.965\end{array}$ & 8.2 \\
\hline 100 & 100.144 & 100.1 & 0.043 & -21.7756 & -21 & 3.536 \\
\hline 110 & 102.5751 & 104 & 1.357 & -27.7968 & -28.7 & 3.17 \\
\hline 120 & 103.3741 & 103.6 & 0.222 & -34.458 & -36.26 & 4.9 \\
\hline 130 & 102.6015 & 102.4 & 0.19 & -41.6417 & -41.39 & 0.57 \\
\hline 140 & 100.354 & 100.8 & 0.456 & -49.2026 & -50.39 & 2.7 \\
\hline 150 & 96.76022 & 96.82 & 0.061 & -56.9715 & -53.52 & 5.9 \\
\hline 160 & 91.97698 & 92.6 & 0.68 & -64.7599 & -62 & 4.21 \\
\hline 170 & 86.18382 & 85.67 & 0.59 & -72.3653 & -68.38 & 5.555 \\
\hline 180 & 79.5774 & 82.7 & 3.771 & -79.5774 & -78.3 & 1.59 \\
\hline
\end{tabular}




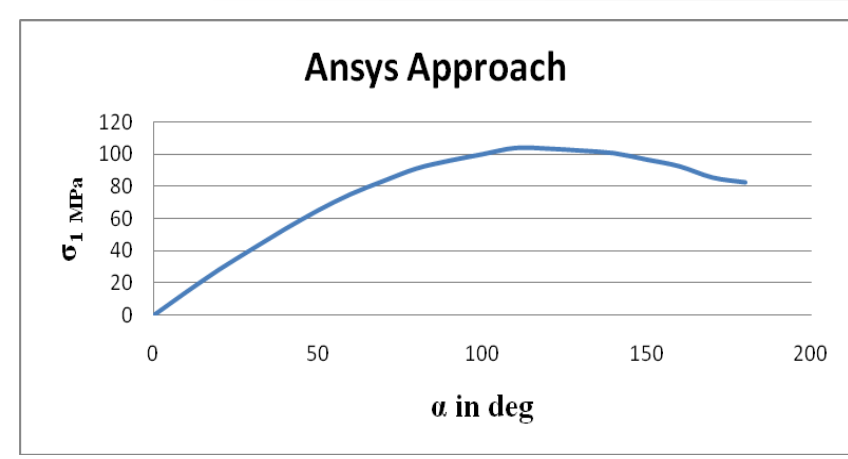

Figure 7 (A): Variation Of ANSYS Values Of Principal Stress $\left(\Sigma_{1}\right)$.

\section{RESULTS AND DISCUSSIONS}

Results of above analysis are tabulated in Table 1 and plotted in figure 7 (a). At any cross section making an angle ' $\alpha$ ' the applied force ' $F$ ' induces transverse shear stress, torsional shear stress and bending stress. Magnitudes of these stresses will be varying over the cross section.

For semi circle curved beam $\left(0^{0}<\alpha<180^{\circ}\right)$ case with end Out-Of-Plane load the principal stress in geometry is due to combined effect of Bending stress because of Bending arm as well as Torsional stress because of Twisting arm. Maximum principle stress increases from free end to fixed end up to a certain extent and goes high at that extent then goes on decreasing towards fixed end. Here we can observe the max value of maximum principle stress is at $\alpha=120^{\circ}$.

Table 1 tabulates the values of maximum principal stress $\left(\sigma_{1}\right)$ and minimum principal stress $\left(\sigma_{2}\right)$ at points $\mathrm{R}$ for different values of $\alpha$ varying from $10^{\circ}$ to $180^{\circ}$. Torsional shear stress also increases gradually as $\alpha$ increase and is maximum at the fixed end. The values of principal stresses at the extreme points $\mathrm{R}$ on the cross section for different angles $\alpha$ shown that, the maximum principal stress $\sigma_{1}$ is tensile in nature and minimum principal stress $\sigma_{2}$ is compressive. Magnitude of maximum principal stress increases gradually from the loading and acquires maximum value at $\alpha=120^{\circ}$ and then decreases and becomes equal to maximum torsional shear stress at the fixed end. The minimum principal stress acquires its minimum value at the fixed end. At the fixed end the magnitude of maximum principal stress is numerically equal to the minimum principal stress but is of opposite sign. This clearly indicates that at the fixed end of semi circular beam subjected to outof-plane load a state of pure shear prevails.

\section{ACKNOWLEDGEMENT}

We thankful to all staff members of JNNCE, Shimoga and ATMECE, Mysore for their support for completing the work.

\section{REFERENCES}

[1] Theoretical Analysis Of Semi Circular Curved Beam Subjected To Out-Of-Plane Load- D S Ramakrishna \& Rakshith N, International Journal of Mechanical Engineering (IJME), IASET, ISSN(P): 2319-2240; ISSN(E): 2319-2259 Vol. 3, Issue 6, Nov 2014, 37-44.

[2]. Numerical solution of curved pipes submitted to inplane loading conditions. - E.M.M. Fonseca, F.J.M.Q. de Melo ELSEVIER-2009

[3]. Simple Mechanical Model of Curved Beams by a 3D Approach.-Stefano Lenci and Francesco ClementiACSEjuly 2009

[4]. A Curved Beam Element and Its Application to Traffic Poles.-Thesis by-Cheng Zhang -Department of Mechanical and Industrial Engineering University of Manitoba Winnipeg, Manitoba-1998

[5]. A Finite Circular Arch Element Based on Trigonometric Shape Functions.-H. Saffari and R. Tabatabaei-2007

[6]. End-loaded shallow curved beams.-Clive L. Dym, F.ACSE-2011

[7]. In-Plane Vibrations of Circular Curved Beams With A Transverse Open Crack-H. R. Öz and M. T. DasMathematical And Computational Applications, Vol. 11, No. 1, Pp. 1-10, 2006

[8]. Theory And Application of Naturally Curved And Twisted Beams With Closed Thin-Walled Cross SectionsAimin Yu - Rongqiang Yang - Ying Hao-Journal Of Mechanical Engineering 55(2009)12, 733-741.

\section{BIOGRAPHIES}

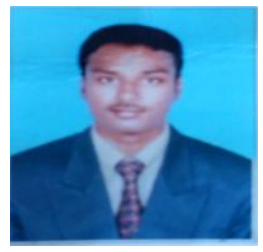

Rakshith N working as a Assistant Professor in Department of Mechanical Engineering in ATMECE, Mysore and having an experience of 1 and half years.

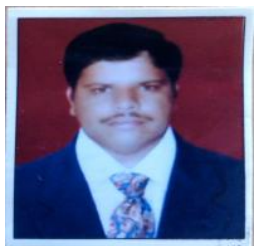

Chethan S working as a Assistant Professor in Department of Mechanical Engineering in ATMECE, Mysore and having an experience of 9 years.

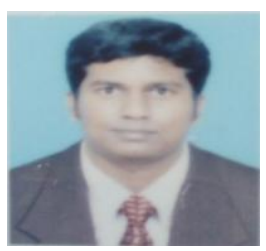

Manjunatha $\mathrm{H}$ S working as a Assistant Professor in Department of Mechanical Engineering in ATMECE, Mysore and having an experience of 7 years.

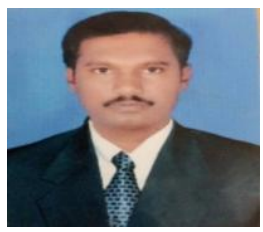

Suresh Kumar $\mathrm{S}$ working as a Assistant Professor in Department of Mechanical Engineering in ATMECE, Mysore and having an experience of 10 years. 